Review Article

\title{
Prooxidant Effects of Epigallocatechin-3-Gallate in Health Benefits and Potential Adverse Effect
}

\author{
Jie Ouyang $\mathbb{D}^{1,2,3}$ Kun Zhu $\mathbb{D}^{1,2,3}$ Zhonghua Liu $\mathbb{D}^{1,2,3}$ and Jianan Huang $\mathbb{D}^{1,2,3}$ \\ ${ }^{1}$ National Research Center of Engineering Technology for Utilization of Functional Ingredients from Botanicals, \\ Hunan Agricultural University, Changsha, China \\ ${ }^{2}$ Collaborative Innovation Centre of Utilization of Functional Ingredients from Botanicals, Hunan Agricultural University, \\ Changsha, China \\ ${ }^{3}$ Key Laboratory of Tea Science of Ministry of Education, Hunan Agricultural University, Changsha, China
}

Correspondence should be addressed to Zhonghua Liu; larkin-liu@163.com

Received 2 June 2020; Accepted 29 July 2020; Published 12 August 2020

Academic Editor: Marco Malaguti

Copyright (c) 2020 Jie Ouyang et al. This is an open access article distributed under the Creative Commons Attribution License, which permits unrestricted use, distribution, and reproduction in any medium, provided the original work is properly cited.

Epigallocatechin-3-gallate (EGCG) is the major polyphenolic compound present in green tea and is generally regarded as an effective antioxidant. However, its chemical reactivity makes it susceptible to generate reactive oxygen species (ROS) via autooxidation and exhibit prooxidant effects. The prooxidant actions of EGCG could play a dual role, being both beneficial and harmful. This review summarized recent research progress on (1) the anticancer, antiobesity, and antibacterial effects of EGCG and (2) the possible toxicity of EGCG. The major focus is on the involvement of prooxidant effects of EGCG and their effective doses used. Considering dosage is a crucial factor in the prooxidant effects of EGCG; further studies are required to find the appropriate dose at which EGCG could bring more health benefits with lower toxicity.

\section{Introduction}

Tea is the second most popular beverage consumed in the world, next to water. Green tea is a kind of nonfermented tea produced from the plant Camellia sinensis. It is favored by people for its fresh flavor and health benefits and consumed worldwide, especially in East Asian countries.

Green tea contains caffeine and polyphenolic compounds known as catechins. Catechins are the primary bioactive substances and present significant biological properties. Catechins constitute up to $30-40 \%$ of tea leaves' dry weight, among that EGCG is the main and the most abundant catechin $[1,2]$. EGCG has been traditionally regarded as beneficial, mainly ascribed to its antioxidant action [3]. The antioxidant effects of EGCG are manifested in scavenging free radicals in the body and inhibiting the formation of ROS [4]. The results of earlier studies suggested that EGCG could decrease the risk of several human disorders associated with oxidative stress [5].
On the other hand, EGCG also displays significant prooxidant effects, usually under high-dose conditions. The prooxidant actions of EGCG play a dual role, being both beneficial and harmful. While achieving desired outcomes in chronic disease prevention and treatment, reports about the toxicity of EGCG are also emerging [6]. A growing body of evidence continues to demonstrate a variety of harmful effects from excessive consumption of green tea or oral administration of high-dose EGCG supplement [7]. High doses of EGCG not only cause cytotoxicity in vitro but also result in living body hepatotoxicity, nephrotoxicity, and gastrointestinal disorders (vomiting and diarrhea) [6].

The oral bioavailability of EGCG is not so profound in healthy humans as it was only $0.2-2 \%$ of the total ingestion [8]. Most of the ingested EGCG is absorbed in the small intestine and substantially degraded in the large intestine by microbiota action [9]. The effective dosage of EGCG might be close to or higher than the toxic dosage in practical applications, considering its low bioavailability. Therefore, it is 
necessary to understand the potential toxicity, doses, and usage of EGCG. In this review, the prooxidant effects of EGCG in health benefits and adverse effects were discussed, especially concerning their underlying mechanisms involved and doses used. This review is aimed at harnessing the prooxidant effects of EGCG for human health maintenance while avoiding toxicity, thereby better guiding the safety consumption of green tea and EGCG.

\section{Chemical Structure and Autooxidation of EGCG}

Basic catechins contain two or more aromatic rings. Hydroxyl group on carbon three position and/or the higher degree of hydroxylation of the $\mathrm{B}$ ring would be primarily responsible for the potent antioxidant activities of catechins (Figure 1(a)) [10]. Previous structure-activity relationship studies of catechins have demonstrated the importance of the number and location of the phenolic hydroxyl groups on antioxidative capacity [1]. EGCG has the remarkable potential to scavenge radicals and chelate metal ion. These abilities could be ascribed to the presence of dihydroxy and trihydroxy groups in A ring, B ring, and D ring (Figure 1(b)) [11].

The catechol structure of EGCG makes it susceptible to degradation via autooxidation (Figure 2). Under normal physiological conditions ( $\mathrm{pH} 7.4,37^{\circ} \mathrm{C}$ ), EGCG is autooxidized and converted to o-quinone through nonenzymatical dehydrogenation of phenolic hydroxyl groups at B ring [12]. When the cell culture medium is exposed in the air, EGCG could be oxidized by oxygen and yields superoxide anion radicals $\left(\mathrm{O}_{2}{ }^{-}\right)$and EGCG radicals (EGCG). $\mathrm{O}_{2}{ }^{-}$and EGCG are essential intermediate products in EGCG autooxidation. $\mathrm{O}_{2}{ }^{-}$and oxygen could function as oxidants for further oxidation of EGCG, finally resulting in the formation of o-quinone, accompanying the generation of hydrogen peroxide $\left(\mathrm{H}_{2} \mathrm{O}_{2}\right) \cdot \mathrm{O}_{2}{ }^{-}$could also form substantial amounts of $\mathrm{H}_{2} \mathrm{O}_{2}$ via disproportionation reaction [13]. One EGCG molecule could produce more than two $\mathrm{H}_{2} \mathrm{O}_{2}$ molecules in phosphate buffer at neutral $\mathrm{pH}$ [14].

Autooxidation of EGCG generates substantial ROS. The ROS comprises singlet oxygen, hydroxyl radicals, superoxide, peroxides, and $\mathrm{H}_{2} \mathrm{O}_{2} \cdot \mathrm{H}_{2} \mathrm{O}_{2}$ is in a dominant position and usually is regarded as a toxic agent. When the ROS level exceeds cellular antioxidant capacity, oxidative stress will occur. In other words, this is the result of an imbalance between prooxidant and antioxidant effects. Inclusion of antioxidant defense enzymes such as catalase (CAT) and superoxide dismutase ( $\mathrm{SOD}$ ) could minimize $\mathrm{H}_{2} \mathrm{O}_{2}$ level, which is essential to maintain the redox balance.

The concentration of EGCG in the cell environment seems to be a primary factor in explaining its prooxidant effects [15]. For example, EGCG treatment alone diminished DNA strand breakage of human blood lymphocytes at low concentrations (0.1-0.01 $\mu \mathrm{M})$, while it induced DNA strand breakage at higher concentration (1-100 $\mu \mathrm{M})$ [16]. Thus, EGCG acts as an effective antioxidant at low doses (within the range of high nanomolar and low micromolar levels), while EGCG represents a prooxidant at high doses. However, this blurred boundary might vary depending on the type of radical stimulants, cellular environment, and duration of exposure to EGCG [17].

\section{Health Benefits}

Until now, EGCG has been a major research subject within the field of health-promoting effects. The potential role of the prooxidant effects of EGCG in cancer and obesity prevention and treatment, as well as the antibacterial actions, achieved demonstrable results in previous studies.

3.1. Prooxidant Effects and Anticancer Activity of EGCG. Cancer is one of the most common and life-threatening diseases occurring among humankind. EGCG, as a natural product, has drawn a great deal of attention from both the scientific community and the general public. Indeed, EGCG has shown both prophylactic and therapeutic efficacy in multiple human cancers. Several mechanisms have been proposed to account for the inhibitory action of EGCG against cancer formation and growth. The prooxidant effects of EGCG were thought to be potential mechanisms for anticancer action. The anticancer mechanisms varied depending on the cell type, dose, and/or time of treatment (Table 1) [18-36].

Apoptosis is the best-described form of programmed cell death. The induction of apoptosis represents a universal and ideal therapeutic strategy for cancer control. Cell apoptosis could be triggered by either the intrinsic mitochondrial pathway or the external death receptor pathway [37]. The mitochondrial pathway could be induced by intracellular stresses, such as oxidative stress.

The apoptosis-triggering effects of ROS have been noted in vitro (Table 1). EGCG inhibited cell growth in a dose-dependent manner, and the decrease in the number of viable cells was mainly due to apoptosis caused by the EGCG-induced intracellular ROS. As early as the last century, scientists found that EGCG induced $\mathrm{H}_{2} \mathrm{O}_{2}$ formation in human lung cancer cell lines H661 and 21BES, and exogenously added CAT completely prevented EGCGinduced cell apoptosis, which suggested that $\mathrm{H}_{2} \mathrm{O}_{2}$ is involved in the apoptosis process provoked by EGCG [27]. Similar actions were also found in various cancers and tumor cells (Table 1). Thioredoxin (Trx) and thioredoxin reductase (TrxR) are pivotal regulators of cellular redox homeostasis. Decreased Trx/TrxR activity might contribute to the increased ROS level. High concentration of EGCG inactivated Trx/TrxR via the formation of EGCGTrx1 and EGCG-TrxR conjugates, which was linked to the elevation of ROS level in HeLa cells, and further promoted cancer cell death [22]. Moreover, one of the biochemical hallmarks of apoptosis is genomic DNA fragmentation. Chen et al. performed the DNA fragmentation assay in the SKOV-3 cells, indicating that EGCG induced apoptosis by causing DNA damage [18]. This result was consistent with other studies in ovarian and cervical cancer cells [21, 32].

In terms of molecular mechanisms, intrinsic apoptosis leads to the release of mitochondrial cytochrome c. After being released into the cytoplasm, cytochrome $\mathrm{c}$ stimulates 
<smiles>Oc1cc(O)c2c(c1)OC(c1cc(O)c(O)c(O)c1)C(O)C2</smiles>

(a)<smiles>CC1Cc2c(O)cc(O)cc2OC1c1cc(O)c(O)c(O)c1</smiles>

(b)

Figure 1: (a) Basic structure of catechins. (b) Chemical structure of EGCG.

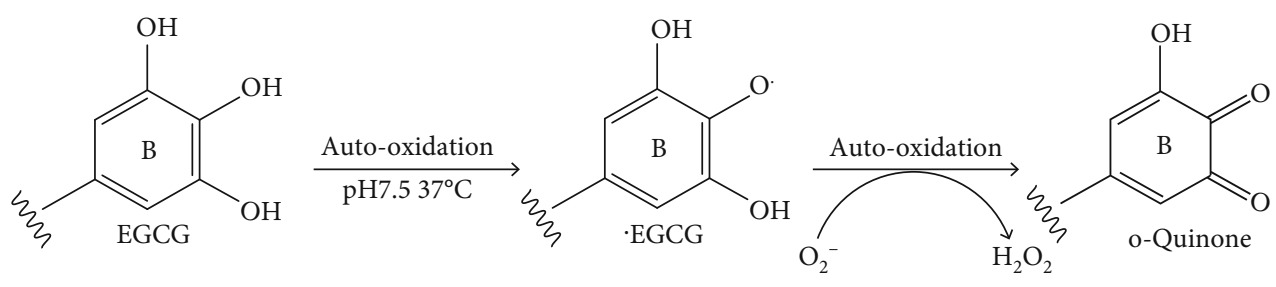

FIGURE 2: Superoxide-mediated chain reaction: the formation of o-quinone.

apoptosome formation, followed by activation of caspase cascades [37]. EGCG-mediated mitochondrial ROS could promote cytochrome $\mathrm{c}$ release to the cytosol. The antiproliferative action of EGCG on prostate cancer and breast cancer is mediated through apoptosis as evident from caspase-9 $[19,36]$. The cells susceptible to EGCG-induced apoptosis also showed activation of caspase-3 [38]. Moreover, the increased ROS level was observed to result in the stimulation of mitogen-activated protein kinase (MAPK) [39]. The MAPK signaling pathway, including extracellular signalregulated kinase (ERK), Jun N-terminal kinase (JNKs), and p38, plays a vital contribution in cell proliferation, differentiation, apoptosis, and stress response. EGCG induced oxidative stress via generation of ROS and thereafter activated the JNK pathway, leading to changes in mitochondrial membrane potential and release of cytochrome $c$ in HT-29 human colon adenocarcinoma cells and MIA PaCa-2 pancreatic cancer cells [24, 34]. Together, these results suggest that EGCG-induced apoptosis is mediated through ROS generation and might subsequently activate the cell intrinsic pathway [33].

In the presence of transition metals such as copper and iron, $\mathrm{H}_{2} \mathrm{O}_{2}$ could convert to a potent oxidant hydroxyl radi$\mathrm{cal}$ via the Fenton reaction. Nakagawa et al. found that EGCG $(12.5-50 \mu \mathrm{M})$ produced $\mathrm{H}_{2} \mathrm{O}_{2}$ and triggered Fenton reaction to form highly toxic hydroxyl radicals, which resulted in lymphoblastic leukemia Jurkat cell death [29]. In the presence of $\mathrm{Fe}(\mathrm{III})$ and $\mathrm{Cu}(\mathrm{II})$, EGCG $(5-20 \mu \mathrm{M})$ induced DNA damage in HL-60 cells, as 8-oxo-7,8-dihydro-2' -deoxyguanosine (8oxodG) content increased, which was a characteristic of oxidative DNA damage [40]. Nevertheless, no significant increase in 8-oxodG was observed in $\mathrm{H}_{2} \mathrm{O}_{2}$-resistant colon HP100 cells, suggesting that $\mathrm{H}_{2} \mathrm{O}_{2}$ was involved in cellular DNA damage. EGCG could inhibit cell proliferation and induce apoptosis through cellular DNA breakage in different cancer cell lines [41]. Such DNA breakage involved the mobilization of endogenous copper ions and the generation of ROS. Moreover, the observation of site specificity of DNA damage by EGCG is valuable. $\mathrm{Cu}(\mathrm{II})$-mediated DNA damage by EGCG occurred most frequently at $\mathrm{T}$ and $\mathrm{G}$ residues [40]. EGCG was able to mobilize endogenous copper ions and generate hydroxyl radicals in situ [42]. Hydroxyl radicals served as the proximal DNA cleaving agent, leading to DNA breakage in the nuclei. This result was possibly due to the interaction of EGCG with chromatin-bound copper ions, and then, the nondiffusible hydroxyl radicals were formed at the binding site. Hence, hydroxyl radical generated nearby DNA was well established as the cause of strand scission. Because the concentration of copper is significantly very high in various malignancies, EGCG could induce cancer cell death through the metal ion-dependent pathway [41]. This pathway was independent of mitochondria-mediated programmed cell deaths. Such action involved in metal ionmediated DNA cleavage would be an important mechanism of anticancer properties of EGCG.

In addition to being transported into the cell, EGCG could also function on the cell membrane fraction to regulate the surface growth factor receptor [43]. Earlier studies found that autooxidation of EGCG led to epidermal growth factor receptor (EGFR) inactivation in human esophageal cancer 
TABLE 1: Role of prooxidant effects in the anticancer activity of EGCG based on cell culture studies.

\begin{tabular}{|c|c|c|c|c|}
\hline Cell lines & $\begin{array}{c}\text { EGCG } \\
\text { concentration }\end{array}$ & Time & Biological effects & References \\
\hline \multicolumn{5}{|l|}{ Bladder cancer } \\
\hline NBT-II & $10-40 \mu \mathrm{M}$ & $24-72 \mathrm{~h}$ & Induced early apoptosis through DNA damage & [18] \\
\hline \multicolumn{5}{|l|}{ Breast cancer } \\
\hline MCF-7 & $10-50 \mu \mathrm{g} / \mathrm{mL}$ & $48 \mathrm{~h}$ & $\begin{array}{l}\text { Induced cell growth inhibition and apoptosis by downregulating survivin } \\
\text { expression via suppressing the AKT pathway and activating caspase-9 }\end{array}$ & {$[19]$} \\
\hline MCF-7 & $10-400 \mu \mathrm{M}$ & $6 \mathrm{~h}$ & $\begin{array}{l}\text { Induced apoptosis at low doses via activation of JNK, caspase-9, and caspase-3, } \\
\text { while inducing necrosis at high doses, which is related to differences in ROS } \\
\text { generation and ATP levels }\end{array}$ & {$[20]$} \\
\hline \multicolumn{5}{|l|}{ Cervical cancer } \\
\hline HeLa & $50 \mu \mathrm{M}$ & $\begin{array}{l}24 \text { and } \\
48 \mathrm{~h}\end{array}$ & Increased cell death through DNA damage & {$[21]$} \\
\hline HeLa & $25-200 \mu \mathrm{M}$ & $1 \mathrm{~h}$ & Induced cell death through generation of ROS and inactivation of $\operatorname{Trx} / \operatorname{TrxR}$ & [22] \\
\hline \multicolumn{5}{|l|}{ Colon cancer } \\
\hline HCT116 & $50-100 \mu \mathrm{M}$ & $24 \mathrm{~h}$ & $\begin{array}{c}\text { Induced apoptosis through induction of ROS and epigenetic modulation of } \\
\text { apoptosis-related gene expression }\end{array}$ & [23] \\
\hline HT-29 & $25-250 \mu \mathrm{M}$ & $36 \mathrm{~h}$ & $\begin{array}{l}\text { Induced apoptotic cell death via activating the JNK pathway, accompanying } \\
\text { mitochondrial transmembrane potential transition and cytochrome c release; } \\
\qquad \mathrm{IC}_{50} \text { was } \sim 100 \mu \mathrm{M}\end{array}$ & [24] \\
\hline \multicolumn{5}{|c|}{ Endometrial carcinoma } \\
\hline Ishikawa & $25-150 \mu \mathrm{M}$ & $48 \mathrm{~h}$ & $\begin{array}{l}\text { Induced apoptosis via ROS generation and p38 MAP kinase activation; } \\
\qquad \mathrm{IC}_{50} \text { was } 132 \mu \mathrm{M}\end{array}$ & [25] \\
\hline \multicolumn{5}{|l|}{ Esophageal cancer } \\
\hline KYSE 150 & $20 \mu \mathrm{M}$ & $8 \mathrm{~h}$ & Inactivated EGFR by superoxide generated from autooxidation of EGCG & {$[26]$} \\
\hline \multicolumn{5}{|l|}{ Lung cancer } \\
\hline H661 and H1299 & $20-100 \mu \mathrm{M}$ & $48 \mathrm{~h}$ & $\begin{array}{l}\text { Displayed strong growth inhibitory effects against lung tumor cell lines; } \\
\qquad \mathrm{IC}_{50} \text { was } 20 \mu \mathrm{M}\end{array}$ & [27] \\
\hline H1299 & $10-50 \mu \mathrm{M}$ & $24 \mathrm{~h}$ & Inhibited cell growth through induction of ROS; $\mathrm{IC}_{50}$ was $20 \mu \mathrm{M}$ & {$[28]$} \\
\hline \multicolumn{5}{|c|}{ Lymphoblastic leukemia } \\
\hline Jurkat & $12.5-50 \mu \mathrm{M}$ & $6 \mathrm{~h}$ & Induced apoptosis via $\mathrm{H}_{2} \mathrm{O}_{2}$ production and hydroxyl radical formation & [29] \\
\hline \multicolumn{5}{|l|}{ Myeloma } \\
\hline $\begin{array}{l}\text { IM9, RPMI8226, } \\
\text { and U266 }\end{array}$ & $20-100 \mu \mathrm{M}$ & $24-72 \mathrm{~h}$ & Induced apoptosis by modifying the redox system & {$[30]$} \\
\hline \multicolumn{5}{|l|}{ Oral cancer } \\
\hline $\begin{array}{l}\text { SCC-25 and } \\
\text { SCC-9 }\end{array}$ & $100 \mu \mathrm{M}$ & $1-6 \mathrm{~h}$ & $\begin{array}{l}\text { Reduced cell viability by inducing mitochondria-localized ROS and decreasing } \\
\text { SIRT3 expression }\end{array}$ & [31] \\
\hline \multicolumn{5}{|l|}{ Ovarian cancer } \\
\hline SKOV-3 & $20-50 \mu \mathrm{g} / \mathrm{mL}$ & $2 \mathrm{~d}$ & $\begin{array}{l}\text { Inhibited cell proliferation and induced apoptosis by inhibiting cell cycle arrest and } \\
\text { inducing DNA damage }\end{array}$ & {$[32]$} \\
\hline \multicolumn{5}{|l|}{ Pancreatic cancer } \\
\hline PANC-1 & $20-60 \mu \mathrm{M}$ & $12 \mathrm{~h}$ & $\begin{array}{l}\text { Induced apoptosis through generation of ROS, as well as caspase- } 3 \text { and } \\
\text { caspase- } 9 \text { activation }\end{array}$ & [33] \\
\hline MIA PaCa-2 & $100-200 \mu \mathrm{M}$ & $24 \mathrm{~h}$ & $\begin{array}{l}\text { Induced stress signals by damaging mitochondria and ROS-mediated } \\
\text { JNK activation }\end{array}$ & {$[34]$} \\
\hline \multicolumn{5}{|l|}{$\begin{array}{l}\text { Primary effusion } \\
\text { lymphoma }\end{array}$} \\
\hline $\begin{array}{l}\text { BCBL-1 and BC- } \\
1\end{array}$ & $20 \mu \mathrm{g} / \mathrm{mL}$ & $24 \mathrm{~h}$ & Induced apoptosis and autophagy through ROS generation & {$[35]$} \\
\hline \multicolumn{5}{|l|}{ Prostate cancer } \\
\hline PC3 & 1 and $25 \mu \mathrm{M}$ & $48 \mathrm{~h}$ & $\begin{array}{l}\text { Reduced cell survival and increased apoptosis; caused a significant alteration in } \\
\text { caspase- } 9 \text { alternative splicing }\end{array}$ & {$[36]$} \\
\hline
\end{tabular}


cell line KYSE 150 [26]. One possible explanation is that $\mathrm{H}_{2} \mathrm{O}_{2}$ produced from EGCG autooxidation in the cell culture medium could attack and inactivate EGFR, leading to the inhibition of EGFR phosphorylation.

It is worth considering whether high amounts of EGCG could cause damage to normal cells. EGCG-mediated ROS production was particularly observed in cancer cells compared with normal cells. The selectivity of EGCG-induced apoptosis in cancer cells might be due to the differential inducibility of ROS and preferential expression of apoptosis-related genes [23]. Moreover, Tao et al. found that EGCG induced differential mitochondrial dysfunction and oxidative stress in normal and oral cancer cells. These effects were related to the differential modulation of sirtuin 3 (SIRT3) and its downstream targets, including glutathione (GSH) and SOD [31]. Considering the cytotoxicity of EGCG in normal cells, the $\mathrm{IC}_{50}$ value in normal cells was checked and showed to be more than $200 \mu \mathrm{M}$, while that for the corresponding cancer cells was $132 \mu \mathrm{M}$ [25]. These results suggested that cancer cells are more sensitive to EGCG than normal cells, and ROS might be selectively toxic to cancer cells.

In addition to being used as preventive agents individually, EGCG could also be used as adjuvant therapies. Generally, cooperative interaction of two or more agents could target more signaling pathways, thus effectively improving agent chemosensitivity, reducing untoward effects of treatment, expanding the scope of action, and showing higher therapeutic outcomes [44]. Drug resistance is a daunting challenge in cancers. Prooxidant activities of EGCG were proposed to contribute to overcoming drug resistance, highlighted by the fact that $\mathrm{H}_{2} \mathrm{O}_{2}$ production induced by EGCG increased the potency of cisplatin in ovarian cancer cells by three to sixfold [45]. In contrast, cisplatin alone was highly resistant to the treatment in some cancer cell lines. Copper transporter 1 (CTR1) is a critical determinant to increase cisplatin uptake. EGCG could upregulate CTR1 expression through the stimulation of ROS [39]. Simultaneous treatment of arsenic trioxide (ATO) with EGCG showed oxidative-mediated induction of apoptosis in leukemia cancer cells [46]. EGCG acted as a prooxidant and increased intracellular $\mathrm{H}_{2} \mathrm{O}_{2}$, and ATO-induced heme oxygenase-1 (HO-1) provided ferrous iron to increase the Fenton reaction. In both cases, cellular oxidative damage eventually occurred.

In general, under typical cell culture conditions, EGCG has been known to generate (i) extracellular ROS via autooxidative reaction in the cell culture medium, (ii) ROS in cellular mitochondria, and (iii) intracellular ROS through the Fenton reaction upon cell entry (Figure 3). These three pathways contribute differently to cancer cells but eventually cause cell damage and death. Cancer initiation and progression are generally divided into several stages. When EGCG acts as an antioxidant, it might more effectively enhance antioxidant capacity at the cancer prevention stage, whereas when EGCG acts as a prooxidant it might be more critical at suppressing tumor growth stage. One possible supposition is that tumor cells may be more susceptible to oxidative stress, because their increased growth rate and metabolism cause a heightened basal ROS level. The degree of cell proliferation and differentiation seems to be one factor affecting the ROS production ability of EGCG. Future research will be required to determine if EGCG is a much more potent ROS inducer in differentiated than in undifferentiated cancer cells. Although a limited amount of data has shown that these prooxidant effects can occur in vivo, it is essential to understand when and to what extent the antioxidant or prooxidant effects of EGCG are working in different stages of cancers in animal models.

3.2. Prooxidant and Antiobesity Effects of EGCG. Obesity is a metabolic disease characterized by abnormal or excessive fat accumulation. It is generally associated with an increased risk of chronic diseases, including diabetes, hypertension, and dyslipidemia [10]. A large and growing body of studies has investigated the antiobesity effects of EGCG in cellular and animal experiments and the underlying mechanisms.

The clinical manifestations of obesity are adipocyte hyperplasia and hypertrophy. In vitro studies have well demonstrated that EGCG could inhibit adipocyte growth and induce adipocyte death through its prooxidant effects. Hung et al. reported that high concentrations of EGCG (50$400 \mu \mathrm{M})$ reduced the cell viability of preadipocytes by 15$30 \%$, induced the appearance of DNA fragmentation, and increased the activity of the apoptotic enzyme caspase-3 [47]. EGCG was demonstrated to raise ROS level and descend GSH level in preadipocytes and adipocytes, which induced oxidative stress thus resulting in decreased cell number [48].

$5^{\prime}$ AMP-regulated protein kinase (AMPK) represents a metabolite-sensing protein kinase. Hwang et al. (2005) found that the release of ROS by EGCG stimulation could further activate AMPK rapidly in 3T3-L1 adipocytes. A recent study also proved that AMPK was activated by exogenous $\mathrm{H}_{2} \mathrm{O}_{2}$, and this activation was not through direct redox signaling to AMPK, but was a secondary consequence of redox effects on other processes [49].

EGCG activates AMPK via the generation of ROS, subsequently blocks anabolic pathways and promotes the catabolic pathway, and suppresses gluconeogenesis and adipogenesis, consequently leading to body weight reduction and metabolic syndrome alleviation (Figure 4). The activation of AMPK modulates the expression of genes and proteins involved in lipid metabolism, downregulates the expression of fat synthesis proteins, and upregulates lipid catabolism proteins [2]. It was shown that EGCG inhibited the expressions of glucose 6-phosphatase (G6Pase, for gluconeogenesis), phosphoenolpyruvate carboxykinase, (PEPCK, for gluconeogenesis), fatty acid synthase (FAS, for fatty acid synthesis), acetyl-CoA carboxylase (ACC, for fatty acid synthesis), hydroxymethylglutaryl-CoA reductase (HMGR, for cholesterol), sterol regulatory element-binding proteins (SREBPs, for sterol synthesis), peroxisome proliferatoractivated receptor gamma (PPAR $\gamma$, for lipid synthesis and storage), and CCAAT/enhancer-binding protein alpha $(\mathrm{C} / \mathrm{EBP} \alpha$, for adipogenesis) as well as enhanced the expression of acyl-CoA oxidase (ACO, for fatty acid oxidation), peroxisome proliferator-activated receptor alpha (PPAR $\alpha$, 


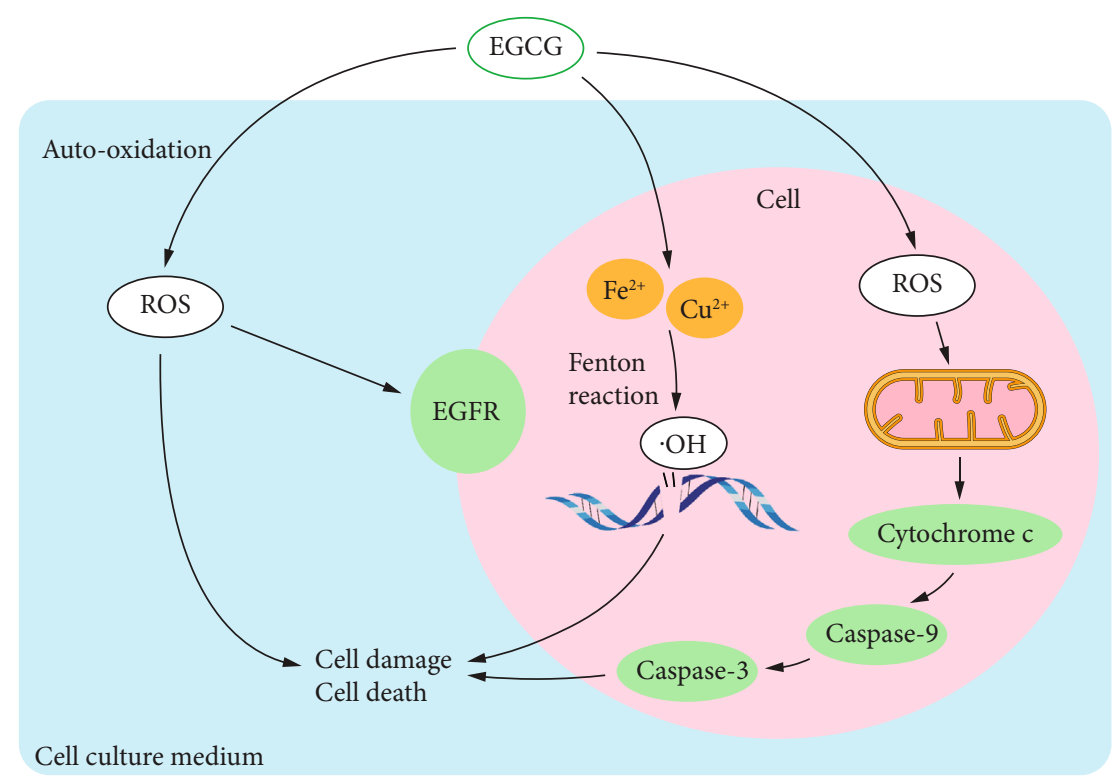

Figure 3: Prooxidant effects of EGCG in cell culture.

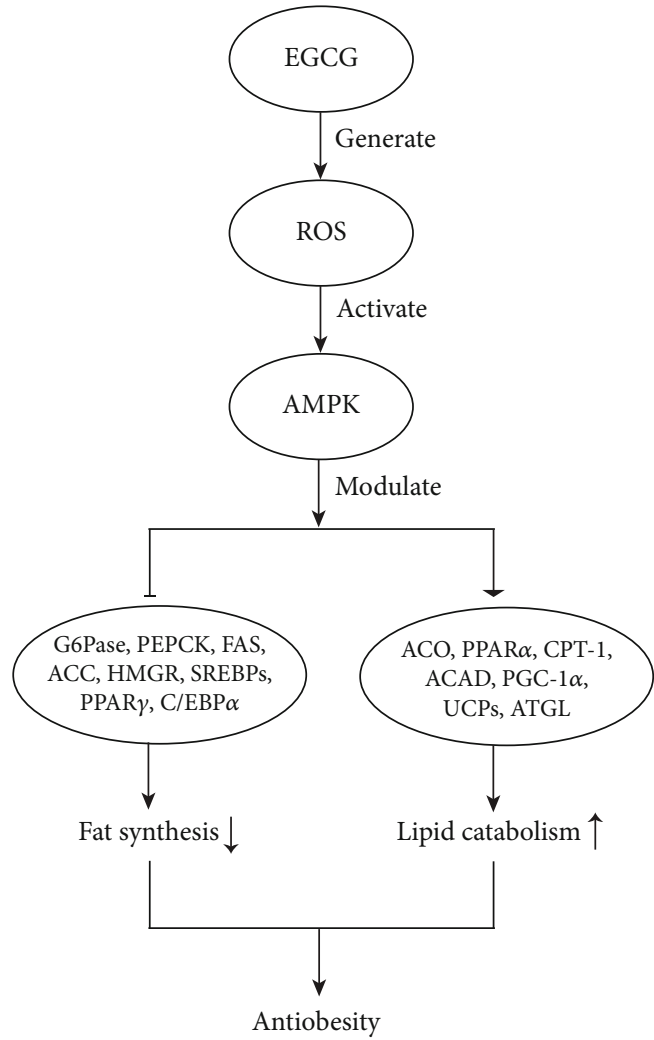

FIGURE 4: Effects of EGCG on lipid metabolism via ROS and AMPK.

for fatty acid oxidation), carnitine palmitoyltransferase-1 (CPT-1, for fatty acid oxidation), acyl-CoA dehydrogenase (ACAD, for fatty acid oxidation), peroxisome proliferatoractivated receptor gamma coactivator- $1 \alpha$ (PGC- $1 \alpha$, for fatty acid oxidation), uncoupling proteins (UCPs, for thermogenesis), and adipose triglyceride lipase (ATGL, for triglyceride hydrolysis) [50-54].
Accordingly, the prooxidant effects of EGCG play a vital role in preventing the initiation and progression of obesity. EGCG could cause oxidative stress thus damaging adipocyte directly and activating AMPK and then affecting relative genes and protein expression and signal transduction in various tissues indirectly. However, the increase of oxidative stress in fat accumulation might be an important pathogenic mechanism of obesity-related metabolic syndrome, such as diabetes. Firm conclusions as to whether prooxidant effects of EGCG could perform on body weight, body fat, and adipose weight in humans will require more thorough clinical studies.

3.3. Prooxidant and Antibacterial Effects of EGCG. EGCG exhibits a broad spectrum of bactericidal activity against various bacteria. Its bactericidal effects include damage to the bacterial cell membrane and inhibition of fatty acid synthesis and enzymatic activity [55]. $\mathrm{H}_{2} \mathrm{O}_{2}$, which is generated by EGCG, appears to play an indispensable role in the bactericidal actions of EGCG. The bactericidal action of EGCG was related to $\mathrm{H}_{2} \mathrm{O}_{2}$ level, as bactericidal action was inhibited by the increase of CAT concentration [14]. EGCG was found to have bactericidal activity at higher concentrations in the Salmonella assay, highly correlated with $\mathrm{H}_{2} \mathrm{O}_{2}$ production [56]. EGCG showed a dose-dependent $(100-1000 \mu \mathrm{M})$ inhibition on Escherichia coli (E. coli) OP50 strain growth [57]. This inhibitory action was associated with a profound increase in intracellular oxidative stress caused by EGCG. Hence, the use of EGCG as a prooxidant is well supported by these studies.

EGCG was shown to have broad antibacterial spectrum effects on both gram-positive and gram-negative bacteria. Nevertheless, EGCG might function through different mechanisms against gram-positive and gram-negative bacteria. Intracellular ROS level was determined by flow cytometry. The results indicated that damage on gram-negative E. coli cell walls was induced by EGCG depending on $\mathrm{H}_{2} \mathrm{O}_{2}$ release 
[58]. In contrast, the damages on gram-positive Staphylococcus aureus resulted from a combination between EGCG and peptidoglycan layer [59]. Because the outer membrane of gram-negative bacteria was mainly composed of negatively charged lipopolysaccharides, which could resist the destruction of EGCG, they are less susceptible to EGCG than gram-positive bacteria [57].

Bacterial cell membrane damage not only prevents the binding of bacteria to host cells but also inhibits the ability of the bacteria to combine with each other and form biofilms [55]. EGCG was known to attack the lipid bilayer of bacterial cell membranes, leading to physical disruption of the membrane [59]. As for the cell walls, results from atomic force microscopy suggested that the subminimum inhibitory concentrations of EGCG treatment $(60-250 \mathrm{mg} / \mathrm{L})$ to E. coli O157:H7 strains could lead to temporary changes in the cell walls (Cui et al., 2012). Such changes were due to the damage caused by $\mathrm{H}_{2} \mathrm{O}_{2}$ generated from EGCG. Moreover, EGCG caused cell membrane damage via increased intracellular ROS level and led to potassium leakage. These are potentially conducive to the antibiofilm efficacy of EGCG against Vibrio mimicus, which is a food-borne pathogen in seafood and water [60].

In addition, EGCG also regulates the expression of oxidative stress-related genes. OxyR and SoxRS systems are activated upon exposure to oxidative stress. OxyR induces katG and SoxRS induce sodA strongly when cells are stressed by exogenous $\mathrm{H}_{2} \mathrm{O}_{2}$ [61]. EGCG treatment upregulated katG and sodA expression in E. coli. These results verified the role of ROS in EGCG-mediated bacterial inhibition [57]. The Cpx system is thought to control protein homeostasis in the cell envelope. When E. coli was exposed to EGCG, apoptosis happened because of ROS formation by the Cpx system [62]. $\mathrm{RpoS}$ is a general stress regulator in response to oxidative stress. EGCG could cause a reduction in the expression for RpoS, indicating that EGCG induced oxidative stress in bacterium models [63].

The potential prooxidant properties of EGCG could be attributed, in part, to its suppressive effects on bacteria. More broadly, research is also needed to determine relative signaling pathways and proteomic factors. EGCG is superexcellent natural products; it could increase the efficacy of bactericidal effect when it aids other fungicides. More recent attention has been focused on the impact of green tea and green tea polyphenols on the intestinal microflora. Whether EGCG intervention would change the diversity of microbiota and lead to microbiota death is also in need of further investigation.

\section{Adverse Effects}

In recent years, EGCG has become one of the most aggressively promoted food supplement products in daily life. EGCG entered the market and its safety has raised queries. The prooxidant effect of EGCG is not necessarily advantageous; they might have implications regarding potential toxicity. Hence, it is necessary to systematically explore the harmful effects of EGCG and the mechanisms.
4.1. Prooxidant and Hepatotoxicity Effects of EGCG. A considerable amount of literature has been published on hepatotoxicity of green tea-derived products [7]. It is noteworthy that the hepatotoxicity of green tea and its derived products was initially found in some diet products. In 2003, after being the cause of liver injury in 13 subjects, France and Spain governments have suspended the marketing of Exolise, which was a weight-loss phytotherapeutical drug [64]. In the past two decades, reports on liver disorders caused by green tea ingestion with overdose of EGCG content have gradually emerged [65].

The liver is a major drug metabolic organ in the body. The bioavailability of EGCG in rats was determined after $60 \mathrm{~min}$ of oral administration $(500 \mathrm{mg} / \mathrm{kg})$ by detecting the concentration of EGCG in plasma and different tissues including the liver. The results showed that the concentration of EGCG in the liver $(48.4 \mu \mathrm{mol} / \mathrm{kg})$ was four times higher than in that in the blood plasma $(12.3 \mu \mathrm{mol} / \mathrm{kg})$ [66]. Moreover, utilizing anatomy, EGCG could trigger liver damage, whereas no visible abnormalities were found in other tissues and organs $[65,67]$. Hence, it could be preliminarily concluded that the liver is the toxic target organ of EGCG.

At the cellular level, EGCG demonstrated cytotoxic effect in cultured rat hepatocytes. It was shown that $200 \mu \mathrm{M}$ EGCG treatment on freshly isolated rat hepatocytes caused timedependent cytotoxicity [68]. The hepatocyte was incubated with EGCG for $24 \mathrm{~h}$, resulting in liver cell function reduced dose dependently [69]. The decrease of lactate dehydrogenase (LDH), a marker of cell membrane damage, was observed in rat hepatocytes [69]. EGCG also caused damage to the outer mitochondrial membrane, by the fact that mitochondrial membrane potential collapsed [68].

In animal experiments (Table 2), the severity of EGCGinduced toxicity is relevant with dose, route of administration, and period of treatment [65, 67, 68, 70-75]. Biochemical and histopathological analysis showed that liver samples of mice displayed different degrees of liver injury. Liver function indexes of plasma alanine aminotransferase (ALT) and aspartate aminotransferase (AST) activity increased in a dose-dependent manner.

Malondialdehyde (MDA) and 4-hydroxynonenal (4HNE) are final products of lipid peroxidation, present biochemical markers of oxidative stress. Metallothionein (MT) and $\gamma$-histone $2 \mathrm{AX}(\gamma \mathrm{H} 2 \mathrm{AX})$ are molecular markers of oxidative stress. Oral high dose of EGCG $(750 \mathrm{mg} / \mathrm{kg} / \mathrm{d})$ to CF1 mice for two days significantly enhanced the formation of MDA in the liver and elevated the expression of hepatic MT and $\gamma \mathrm{H} 2 \mathrm{AX}$ protein and increased positive staining for 4-HNE in liver samples [65]. Intraperitoneal administration of EGCG (55 or $75 \mathrm{mg} / \mathrm{kg} / \mathrm{d}$ ) for five days raised serum 4HNE level, and western blot analysis showed that hepatic $\gamma \mathrm{H} 2 \mathrm{AX}$ was markedly increased [71]. All these biomarkers illustrated that EGCG-triggered hepatotoxicity in vivo was induced by oxidative stress.

Previous pharmacological studies have shown that under normal physiological conditions, EGCG is metabolized through methylation, sulfation, and glucuronidation and then excreted in urine subsequently [76], whereas at toxic doses these pathways might be saturated, and the excessive 
TABLE 2: Hepatotoxicity of EGCG based on animal models.

\begin{tabular}{|c|c|c|c|c|c|}
\hline Animal type & $\begin{array}{c}\text { EGCG } \\
\text { dosage } \\
(\mathrm{mg} / \mathrm{kg} / \mathrm{d})\end{array}$ & $\begin{array}{c}\text { Route of } \\
\text { administration }\end{array}$ & Duration & Results & Reference \\
\hline $\begin{array}{l}\text { Female Swiss } \\
\text { albino mice }\end{array}$ & $\begin{array}{l}108,67.8 \\
21.1, \text { and } \\
\quad 6.6\end{array}$ & i.p. and p.o. & $14 \mathrm{~d}$ & $\begin{array}{c}\text { i.p. treatment increased serum bilirubin markers; p.o. treatment did } \\
\text { not show any dose-dependent changes except ALT marker. } 14 \mathrm{~d} \\
\text { tolerable dose of EGCG was } 21.1 \mathrm{mg} / \mathrm{kg} \text { for i.p. and } 67.8 \mathrm{mg} / \mathrm{kg} \text { for } \\
\text { p.o. }\end{array}$ & {$[67]$} \\
\hline \multirow{3}{*}{$\begin{array}{l}\text { Male } \\
\text { Kunming } \\
\text { mice }\end{array}$} & 55 & \multirow{3}{*}{ i.p. } & $5 \mathrm{~d}$ & $\begin{array}{l}\text { Serum ALT, AST, 4-HNE, IL-2, IL-6, and IL-10 and hepatic } \gamma \mathrm{H} 2 \mathrm{AX} \\
\text { were raised. Hepatic Nrf2-target gene expression was increased. }\end{array}$ & \multirow{3}{*}[70]{} \\
\hline & 70 & & $2 \mathrm{~d}$ & The fatality rate was $100 \%$ & \\
\hline & 125 & & Single dose & $\begin{array}{l}\text { Serum ALT, AST, } 4 \text {-HNE, IL- } 6 \text {, and IL- } 10 \text { and hepatic } \gamma \mathrm{H} 2 \mathrm{AX} \text { were } \\
\text { raised. Hepatic nuclear and cytosolic Nrf2 proteins were suppressed. }\end{array}$ & \\
\hline \multirow{4}{*}{$\begin{array}{l}\text { Male } \\
\text { Kunming } \\
\text { mice }\end{array}$} & 45 & \multirow{4}{*}{ i.p. } & $7 \mathrm{~d}$ & $\begin{array}{l}\text { Mouse growth was not affected. The dosage was considered as } \\
\text { maximum tolerable dose. }\end{array}$ & \multirow{4}{*}[71]{} \\
\hline & 55 and 75 & & $5 \mathrm{~d}$ & $\begin{array}{l}\text { Hepatotoxicity occurred. Major hepatic antioxidant enzymes were } \\
\text { suppressed. Nrf2-mediated rescue response was induced. }\end{array}$ & \\
\hline & $\begin{array}{l}75,100,200 \\
\text { and } 400\end{array}$ & & Single dose & Mice died in a dose-dependent manner. & \\
\hline & 200 & & $\begin{array}{l}4,12 \text {, and } \\
24 \mathrm{~h}\end{array}$ & $\begin{array}{l}\text { The Nrf2 pathway was not activated; Nrf2 and its target genes were } \\
\text { suppressed. }\end{array}$ & \\
\hline \multirow{2}{*}{$\begin{array}{l}\text { Male ND-4 } \\
\text { mice }\end{array}$} & 750 & \multirow{2}{*}{ i.g. } & $5 \mathrm{~d}$ & $\begin{array}{l}\text { ALT was slightly increased. Histopathology of the liver showed } \\
\text { congestion of sinusoids and central and portal veins. }\end{array}$ & \multirow{2}{*}[72]{} \\
\hline & 1500 & & Single dose & $\begin{array}{l}\text { ALT was markedly increased. Histopathology of the liver showed } \\
\text { degenerative hepatocytes and a small number of vacuoles. }\end{array}$ & \\
\hline \multirow{3}{*}{$\begin{array}{l}\text { Male CF-1 } \\
\text { mice }\end{array}$} & 500 & \multirow{3}{*}{ i.g. } & $7 \mathrm{~d}$ & Mouse survival was reduced by $30 \%$. & \multirow{3}{*}{ [65] } \\
\hline & 750 & & $7 \mathrm{~d}$ & $\begin{array}{c}\text { Mouse survival was reduced by } 75 \% \text {. Hepatic MDA, MT, and } \gamma \mathrm{H} 2 \mathrm{AX} \\
\text { were increased. }\end{array}$ & \\
\hline & 1500 & & Single dose & $\begin{array}{c}\text { ALT was increased by } 108 \text {-fold. Mouse survival was reduced by } 85 \% \text {. } \\
\text { EGCG-2' -cysteine and EGCG-2"-cysteine were detected in the } \\
\text { urine. }\end{array}$ & \\
\hline $\begin{array}{l}\text { Wistar rats of } \\
\text { both sexes }\end{array}$ & 1868 & p.o. & Single dose & Mice were lethargic and their respiration was labored. & {$[73]$} \\
\hline $\begin{array}{l}\text { Male CD-1 } \\
\text { mice }\end{array}$ & $\begin{array}{l}100,150 \\
\text { and } 300\end{array}$ & i.p. & Single dose & Plasma ALT was increased. Mice died within $24 \mathrm{~h}$. & {$[68]$} \\
\hline Mice & $\begin{array}{l}50,200, \text { and } \\
400\end{array}$ & i.p. & $24 \mathrm{~h}$ & $\begin{array}{l}\text { EGCG thiol conjugates (EGCG-2' }{ }^{\prime} \text {-cysteinyl and EGCG-2" } \\
\text {-cysteinyl) were detected in the urine. }\end{array}$ & {$[74]$} \\
\hline $\begin{array}{l}\text { Female } \\
\text { Swiss- } \\
\text { Webster mice }\end{array}$ & 50 & i.p. & $7 \mathrm{~d}$ & $\begin{array}{l}\text { 67\% of mice died. Plasma ALT activity was elevated. Severe hepatic } \\
\text { necrosis occurred. }\end{array}$ & {$[75]$} \\
\hline
\end{tabular}

amount of EGCG would be oxidized to form o-quinone, which could react with GSH to form EGCG thiol conjugates [74]. Therefore, it could be inferred that high dose of EGCG results in the accumulation of o-quinones, and the metabolites of o-quinones are biomarkers of oxidative stress. Two EGCG thiol conjugates (EGCG-2' ${ }^{\prime}$-cysteinyl and EGCG-2 ${ }^{\prime \prime}$ -cysteinyl) were detected in the pooled $24 \mathrm{~h}$ urine of mice treated with a dose of 200 or $400 \mathrm{mg} / \mathrm{kg}$ intraperitoneal (i.p.) injection of EGCG. However, EGCG thiol conjugates were not found when the dose was 50 or $2000 \mathrm{mg} / \mathrm{kg} \mathrm{BW}$ i.p. [74]. When CF-1 mice were treated with a single dose of $1500 \mathrm{mg} / \mathrm{kg}$ intragastric (i.g.) administration of EGCG, both EGCG-2'-cysteine and EGCG-2" ${ }^{\prime \prime}$-cysteine were detected in the pooled $24 \mathrm{~h}$ urine [65]. GSH conjugate of
EGCG was also detected in hepatocytes incubated with EGCG [68]. These findings indicated that the formation of detectable amounts of EGCG thiol conjugates appears to result from the administration of toxic doses of EGCG.

Nuclear factor erythroid-related factor 2 (Nrf2), an essential antioxidant transcription factor, regulates the expression of many antioxidant and phase II detoxifying enzyme genes, such as $\mathrm{HO}-1$ and $\mathrm{NADP}(\mathrm{H})$ :quinone oxidoreductase-1 (NQO1), through antioxidant response element (ARE). Under normal metabolic and physiologic states, Nrf2 is repressed in the cytoplasm by Kelch-like ECH-associated protein-1 (Keap1). While under oxidative stress conditions, Nrf2 dissociates from Keap1 and translocates to the nucleus to bind to ARE. The activation of the Nrf2-ARE signaling pathway, 
representing a major cellular defense against oxidative stress, could stimulate the expression of downstream antioxidant enzymes [77]. A previous study revealed that toxic doses of EGCG (55 and $75 \mathrm{mg} / \mathrm{kg}$, i.p.) inhibited hepatic antioxidant enzymes (SOD, CAT, and glutathione peroxidase 1) and exacerbated oxidative damage in hepatocytes [71]. After treatment with EGCG, the expression of Nrf2 decreased in the cytosol and increased in the nucleus, indicative of $\mathrm{Nrf} 2$ activation. As a result, mRNA expression of HO-1, NQO1, and other hepatic Nrf2-target genes was induced in a dose-dependent manner. Accordingly, a conclusion could be made that the molecular mechanisms underlying high-dose EGCG potential toxicity involve activation of the Nrf2-ARE signaling pathway and suppression of major antioxidant enzymes.

It has been suggested that individuals with low catecholO-methyl transferase (COMT) activity might be more susceptible to EGCG-induced hepatotoxicity [78]. COMT is a crucial enzyme in protecting cells from EGCG-mediated oxidative stress and hepatotoxicity, and it could convert EGCG to a methylated conjugate [68]. Treatment with dicumarol, an NQO1 inhibitor, was found to cause a significant increase in EGCG cytotoxicity and ROS formation, suggesting that hepatotoxicity caused by EGCG o-quinone metabolites could be reductively detoxified by NQO1 [68]. Studies conducted by Wang et al. demonstrated that melatonin attenuated EGCG-triggered acute liver damage and associated Nrf2 inhibition at the nonlethal dose of EGCG, suggesting that the Nrf2-mediated signaling pathway plays a vital role in counteracting EGCG toxicity [70].

The oxidative stress induced by high-dose EGCG is dominated in the liver. The hepatotoxicity mechanism of EGCG involves the formation of lipid peroxidation products and EGCG thiol conjugates, as well as activation of the Nrf2-ARE pathway (Figure 5). The adverse events of hepatotoxicity caused by EGCG also occurred in the population. Clinical manifestation includes elevated serum transaminase and bilirubin levels, abdominal pain, and occasional jaundice [7]. Exploring safer and more efficient natural products and using in combination with EGCG, thereby detoxifying EGCG-induced hepatotoxicity, would be a fruitful area for further work.

4.2. Prooxidant and Nephrotoxicity Effects of EGCG. Inoue et al. reported that high-dose EGCG caused nephrotoxicity in dextran sulfate sodium-induced colitis mice, as revealed by increases in serum creatinine, the most reliable biomarker of nephropathy [79]. Moreover, the antioxidant enzymes (HO-1 and NQO1) and heat-shock protein 90 (HSP 90) expressions were downregulated. It can be speculated that high-dose EGCG disrupts kidney functions through the suppression of antioxidant enzymes and heat-shock protein expressions, which might be associated with its prooxidative property.

Since ROS is generated enormously, oxidative stress occurred, and defense systems would be overwhelmed. Several evidences suggest that oxidative stress plays a vital role in the development and progression of diabetes and its related complications [80]. EGCG acts as a prooxidant that might further augment oxidative stress. A previous study

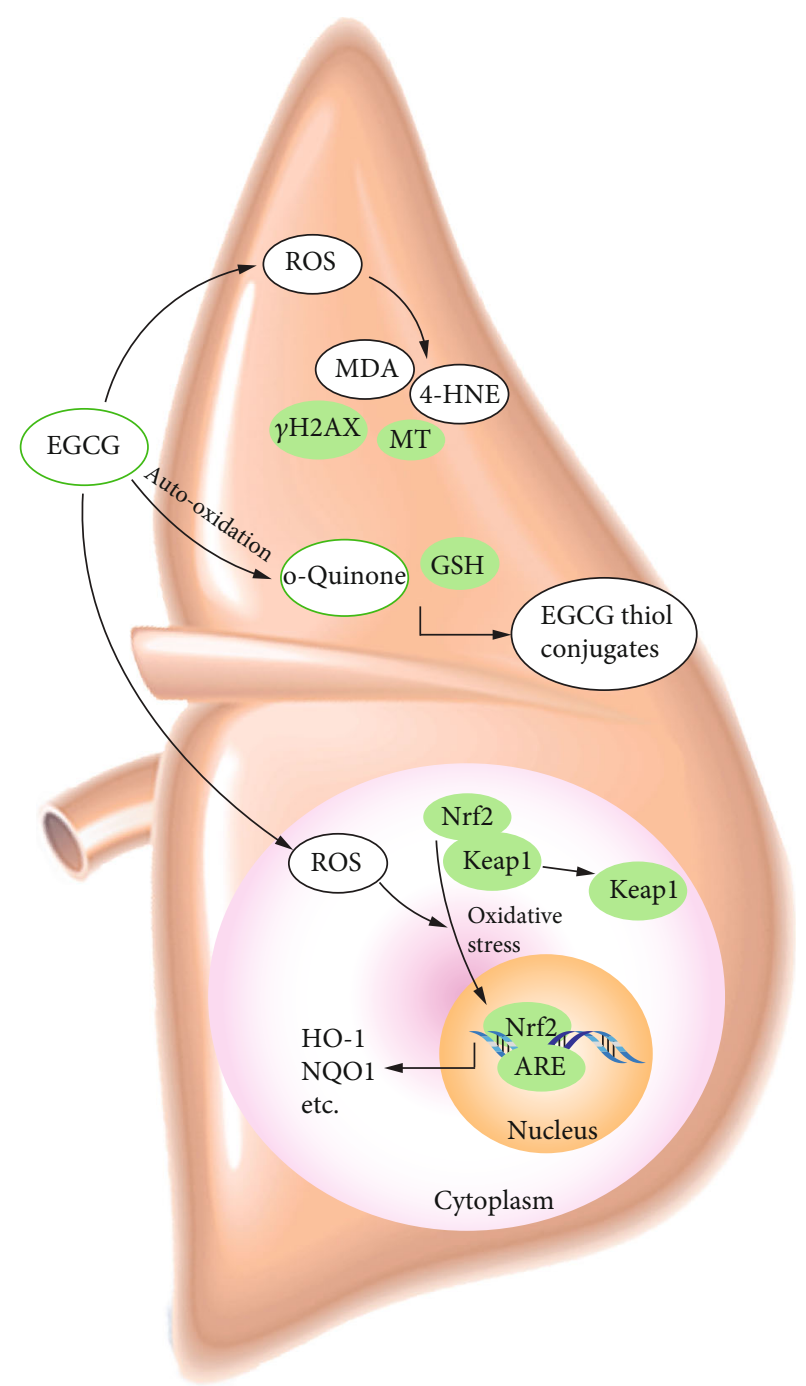

FIGURe 5: The hepatotoxicity mechanism of EGCG.

indicated that EGCG treatment to streptozotocin- (STZ-) induced diabetic mice would result in a deteriorated oxidative stress status [81].

The kidney is a vital organ affected by diabetes. EGCG treatment $(100 \mathrm{mg} / \mathrm{kg} / \mathrm{d}$, i.p. for 4 days) enhanced NADPH oxidase contents, while it reduced total antioxidant capacity and downregulated Nrf2, HO-1, and HSP 90 in STZinduced diabetes mouse kidneys. Histopathological examination confirmed that EGCG could cause kidney damage [81]. In contrast, EGCG might be helpful to inhibit the progression of diabetes through suppressing the increase of blood glucose levels, when the same dose of EGCG $(100 \mathrm{mg} / \mathrm{kg})$ and the same administration route (i.p.) were given to STZinduced diabetic mice for 10 days [82]. These results suggested that EGCG nephrotoxicity could occur even under low dosage. The administration duration might be one of the crucial factors that affect EGCG toxicity. As a result, although many studies have demonstrated the ability of EGCG to mitigate or retard diabetes, patients with diabetes are advised to take EGCG supplements with caution. 
4.3. Prooxidant Effects and Other Adverse Effects of EGCG. Except the liver and kidney, EGCG-induced adverse actions related to its prooxidant effects were observed in other organs and/or tissues. In animal studies, Chu et al. [83] found that EGCG could give a deleterious effect to ocular tissues, as oxidative stress was induced in the plasma, aqueous humor, vitreous humor, cornea, and retina. High-level EGCG would induce SOD1 but suppress CAT expression, resulting in oxidative stress in the retina. The increase of SOD1 would accelerate ROS neutralization rate to form $\mathrm{H}_{2} \mathrm{O}_{2}$, while the decrease of CAT would retard the rate of $\mathrm{H}_{2} \mathrm{O}_{2}$ clearance.

Oxidative stress could lead to the destruction of islet $\beta$-cell and decrease the sensitivity of peripheral tissues to insulin, resulting in type 1 diabetes [84]. A 4-day treatment with EGCG $(5 \mathrm{mg} / \mathrm{kg} / \mathrm{d}$, i.p.) further damaged the $\beta$-cell response to high glucose in STZ-induced diabetic rats [17]. Antioxidant vitamin E blocked the death and dysfunction of $\beta$-cell, suggesting that EGCG acted as a prooxidant.

An in vitro study reported the embryonic toxicity of EGCG. 25-50 $\mu \mathrm{M}$ of EGCG notedly increased apoptosis in mouse blastocysts, decreased cell number, and appeared to impair sequent embryonic development [85]. EGCG induced injury in mouse blastocysts through intrinsic apoptotic signaling processes, because pretreatment with specific inhibitors of caspase- 9 and caspase- 3 effectively blocked apoptosis. This intrinsic apoptosis is related mainly to the prooxidant activities of EGCG.

With respect to cellular DNA, EGCG has obvious damaging activities. In healthy human lymphocytes, 1-100 $\mu \mathrm{M}$ EGCG induced the DNA strand breakage [16]. This finding is consistent with other research that found EGCG (10$100 \mu \mathrm{M})$ causes DNA damage in a dose-dependent manner in human lymphocytes [86]. This oxidative damage results from prooxidant effects of EGCG. It is worthy to note that EGCG has no clastogenic effects in vivo [56].

Another in vitro study found that EGCG-induced oxidative stress in fat cells might be detrimental to health by interfering with the adipocyte endocrine activity [87].

\section{Safe Dose of EGCG}

EGCG-based dietary supplements have been considered as healthy and natural products. Although the toxic doses of EGCG are much higher than those delivered by daily tea consumption, they are more readily achievable in the context of dietary supplements. Hence, it is necessary to discuss the safe dose of EGCG.

In a safety study on EGCG, the genetic, acute, and shortterm toxicity was examined, and a no-observed adverse effect level (NOAEL) of $500 \mathrm{mg} / \mathrm{kg} /$ day EGCG was established [73]. The oral $\mathrm{LD}_{50}$ value of EGCG in rats was found to be between 186.8 (safe) and $1868 \mathrm{mg} / \mathrm{kg}$ (shows toxic effects and animal morbidity and mortality) [73].

As for humans, the NOAEL was reported to be $600 \mathrm{mg} /$ day [88]. The acceptable daily intake (ADI) for $70 \mathrm{~kg}$ adult humans was reported to be $322 \mathrm{mg}$ EGCG/day [88]. Likewise, some European regulatory agencies proposed that the tolerable upper intake level of EGCG should be $300 \mathrm{mg}$ per day for humans [88]. After reviewing the evidence from interventional clinical trials, the European Food Safety Authority (EFSA) concluded that an intake of $800 \mathrm{mg}$ or more of EGCG/day could lead to elevated transaminases [64]. Based on the available data on human adverse event data review, an observed safe level of EGCG might be considered for $704 \mathrm{mg}$ per day in beverage form and $338 \mathrm{mg}$ per day in bolus form [78].

$100 \mathrm{~g}$ dry weight of green tea contains about $7000 \mathrm{mg}$ EGCG, and $100 \mathrm{~g}$ of green tea infusion contains approximately $70 \mathrm{mg}$ EGCG. The mean exposure EGCG from brewed green tea is $321 \mathrm{mg} /$ day in adults [64]. It is challenging to determine a standard safe intake level for EGCG, as the data derived from a large set of human clinical studies might be diverse in designs, durations, and subject populations. Even so, it is important to check the label carefully and calculate the daily intake of EGCG when taking dietary supplements. EGCG intake might require health-based guidance when there are other EGCG sources.

\section{Conclusion and Perspective}

EGCG has a variety of beneficial functions, which could be attributed to its antioxidant properties. However, EGCG could also function as a prooxidant under certain conditions (Figure 6). Its prooxidant effects into the cells were evidenced as oxidative damage to the cell structures, including DNA and lipids. This oxidative damage results from excess ROS produced by EGCG. Several approaches have been proposed to explain how EGCG induces the production of a mass of ROS. They include autooxidation processes of EGCG, presence of transition metals, and mitochondrial ROS. On the one hand, the prooxidant effects of EGCG exhibit salutary effects, namely, induce cancer cell apoptosis, inhibit adipocyte differentiation, and cause bactericidal action. These actions finally result in cell damage or death, including cancer cells, fat cells, and bacterial cells, suggesting that EGCG is a potent cytotoxic agent. On the other hand, the prooxidant nature of EGCG has been questioned, due to the excess intake of EGCG which induced toxicity in animal models and human subjects. High-dose EGCG overproduces ROS, resulting in the damage of antioxidant defense in the body. Local organs, especially the liver, could be involved in injuries to different extents.

According to the gathered data, the oral administration (p.o.) or i.g. is much less toxic than i.p., probably due to the limited systemic bioavailability of oral EGCG. However, under specific conditions, such as fasting and repeated administration, EGCG plasma levels might rise and reach toxic levels [6]. The majority of the toxic effects of EGCG are acute, subacute, and subchronic toxicity. Up to now, far too little attention has been paid to chronic toxicity, which evaluates the toxic effects of EGCG in longer than three months of exposure. Given that consuming green tea and taking supplements are long-term processes, the chronic toxicity of EGCG is an important issue for future research.

Moreover, as the relationship between natural drug metabolism and cytochrome P450 enzymes has gradually 


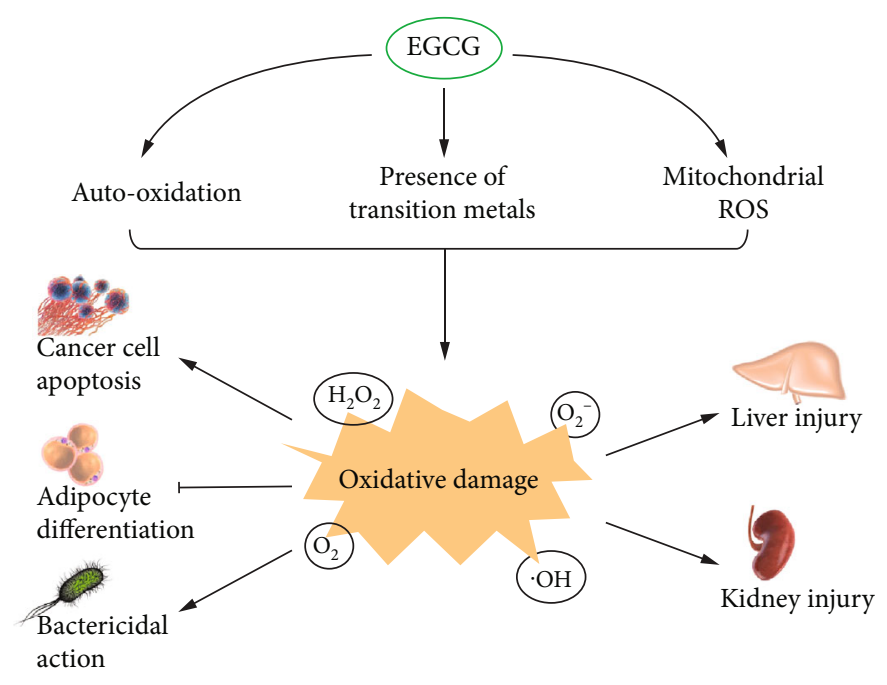

FIgURE 6: The prooxidant effects of EGCG.

been revealed, EGCG might worsen hepatic oxidative stress by influencing drug-metabolizing pathways. The relationship between cytochrome P450 enzyme activation and EGCG metabolism provides an insight for future research on hepatotoxicity mechanism. Cytochrome P450 might interact with EGCG and produce oxygen free radical, thus disrupting mitochondrial membrane potential [89].

Most prooxidant effects of EGCG relevant to health benefit research are based on in vitro studies. There is relatively little clinical trial which might be due to the potential toxicity of high doses of EGCG in human subjects. It is hard to determine when such prooxidant effects transition from beneficial effects to potentially harmful effects. Further research regarding the appropriate doses for human intervention studies would be worthwhile.

The dual function of antioxidant and prooxidant potentials of EGCG is mainly dependent on the dose levels and the biological environments. Some of EGCG-mediated health effects are only affected by concentrations, which are far above the levels obtained by either drinking green tea or taking moderate doses of green tea extract-based dietary supplements. These doses might present to be toxic in some cases. The presence of antioxidants such as melatonin could lower the toxicity of EGCG. Antioxidants might be able to minimize the increase of ROS generation induced by EGCG. Safe and effective food therapeutics searched from natural drugs has provided a new idea for diminishing the potential adverse effects of EGCG. However, the matter of concern is whether a loss of the beneficial effects accompanies the combination of EGCG with other antioxidants. Moreover, due to the Fenton reaction, when transition metal levels are considerably higher, the dosage of EGCG required to elicit prooxidant effects would be significantly lower [42]. Hence, further investigation is needed to optimize the dosage to offer salutary effects with minimal unfavorable effects.

\section{Conflicts of Interest}

The authors report no declarations of interest.

\section{Acknowledgments}

This work was supported by the National Natural Science Foundation of China (grant numbers 31871764, 31801547, and 31471706).

\section{References}

[1] C. Braicu, M. R. Ladomery, V. S. Chedea, A. Irimie, and I. Berindan-Neagoe, "The relationship between the structure and biological actions of green tea catechins," Food Chemistry, vol. 141, no. 3, pp. 3282-3289, 2013.

[2] T. Suzuki, M. Pervin, S. Goto, M. Isemura, and Y. Nakamura, "Beneficial effects of tea and the green tea catechin epigallocatechin-3-gallate on obesity," Molecules, vol. 21, no. 10, p. 1305, 2016.

[3] C. S. Yang, C. T. Ho, J. Zhang, X. Wan, K. Zhang, and J. Lim, "Antioxidants: differing meanings in food science and health science," Journal of Agricultural and Food Chemistry, vol. 66, no. 12, pp. 3063-3068, 2018.

[4] Y. Z. Cai, Mei Sun, Jie Xing, Q. Luo, and H. Corke, "Structureradical scavenging activity relationships of phenolic compounds from traditional Chinese medicinal plants," Life Sciences, vol. 78, no. 25, pp. 2872-2888, 2006.

[5] T.-S. Chen, S. Y. Liou, H. C. Wu et al., "Amino acids with basic amino side chain accelerate the pro-oxidant ability of polyphenolic compounds," Food Chemistry, vol. 134, no. 1, pp. 9-14, 2012.

[6] Z. Bedrood, M. Rameshrad, and H. Hosseinzadeh, "Toxicological effects of Camellia sinensis (green tea): a review," Phytotherapy Research, vol. 32, no. 7, pp. 1163-1180, 2018.

[7] M. Molinari, K. D. S. Watt, T. Kruszyna et al., "Acute liver failure induced by green tea extracts: case report and review of the literature," Liver Transplantation, vol. 12, no. 12, pp. 1892 1895, 2006.

[8] Q. Y. Eng, P. V. Thanikachalam, and S. Ramamurthy, "Molecular understanding of epigallocatechin gallate (EGCG) in cardiovascular and metabolic diseases," Journal of Ethnopharmacology, vol. 210, pp. 296-310, 2018. 
[9] C. Cabrera, R. Artacho, and R. Giménez, "Beneficial effects of green tea-a review," Journal of the American College of Nutrition, vol. 25, no. 2, pp. 79-99, 2006.

[10] T. C. Dinh, T. N. T. Phuong, L. B. Minh et al., "The effects of green tea on lipid metabolism and its potential applications for obesity and related metabolic disorders - an existing update," Diabetes \& Metabolic Syndrome, vol. 13, no. 2, pp. 1667-1673, 2019.

[11] R.-Y. Gan, H.-B. Li, Z.-Q. Sui, and H. Corke, "Absorption, metabolism, anti-cancer effect and molecular targets of epigallocatechin gallate (EGCG): an updated review," Critical Reviews in Food Science and Nutrition, vol. 58, no. 6, pp. 924-941, 2017.

[12] M. Akagawa, T. Shigemitsu, and K. Suyama, "Production of hydrogen peroxide by polyphenols and polyphenol-rich beverages underQuasi-physiological conditions," Bioscience, Biotechnology, and Biochemistry, vol. 67, no. 12, pp. 2632-2640, 2014.

[13] T. Ishii, T. Mori, T. Tanaka et al., "Covalent modification of proteins by green tea polyphenol (-)-epigallocatechin-3-gallate through autoxidation," Free Radical Biology \& Medicine, vol. 45, no. 10, pp. 1384-1394, 2008.

[14] H. Arakawa, M. Maeda, S. Okubo, and T. Shimamura, "Role of hydrogen peroxide in bactericidal action of catechin," Biological \& Pharmaceutical Bulletin, vol. 27, no. 3, pp. 277-281, 2004.

[15] E. Lecumberri, Y. M. Dupertuis, R. Miralbell, and C. Pichard, "Green tea polyphenol epigallocatechin-3-gallate (EGCG) as adjuvant in cancer therapy," Clinical Nutrition, vol. 32, no. 6, pp. 894-903, 2013.

[16] M. Kanadzu, Y. Lu, and K. Morimoto, "Dual function of (-)-epigallocatechin gallate (EGCG) in healthy human lymphocytes," Cancer Letters, vol. 241, no. 2, pp. 250-255, 2006.

[17] S. Y. Yun, S. P. Kim, and D. K. Song, "Effects of (-)-epigallocatechin-3-gallate on pancreatic beta-cell damage in streptozotocin-induced diabetic rats," European Journal of Pharmacology, vol. 541, no. 1-2, pp. 115-121, 2006.

[18] J. J. Chen, Z.-Q. Ye, and M. W. L. Koo, "Growth inhibition and cell cycle arrest effects of epigallocatechin gallate in the NBT-II bladder tumour cell line," BJU International, vol. 93, no. 7, pp. 1082-1086, 2004.

[19] Y. Tang, D. Y. Zhao, S. Elliott et al., "Epigallocatechin-3 gallate induces growth inhibition and apoptosis in human breast cancer cells through survivin suppression," International Journal of Oncology, vol. 31, no. 4, pp. 705-711, 2007.

[20] Y. D. Hsuuw and W. H. Chan, "Epigallocatechin gallate dosedependently induces apoptosis or necrosis in human MCF-7 cells," Annals of the New York Academy of Sciences, vol. 1095, no. 1, pp. 428-440, 2007.

[21] C. Sharma, Q. E. A. Nusri, S. Begum, E. Javed, T. A. Rizvi, and A. Hussain, "(-)-Epigallocatechin-3-gallate induces apoptosis and inhibits invasion and migration of human cervical cancer cells," Asian Pacific Journal of Cancer Prevention, vol. 13, no. 9, pp. 4815-4822, 2012.

[22] H. Zhang, D. Cao, W. Cui, M. Ji, X. Qian, and L. Zhong, "Molecular bases of thioredoxin and thioredoxin reductasemediated prooxidant actions of (-)-epigallocatechin-3-gallate," Free Radical Biology \& Medicine, vol. 49, no. 12, pp. 20102018, 2010.

[23] N. Y. Min, J.-H. Kim, J.-H. Choi et al., "Selective death of cancer cells by preferential induction of reactive oxygen species in response to (-)-epigallocatechin-3-gallate," Biochemical \& Biophysical Research Communications, vol. 421, no. 1, pp. 91-97, 2012.

[24] C. Chen, G. Shen, V. Hebbar, R. Hu, E. D. Owuor, and A. N. T. Kong, "Epigallocatechin-3-gallate-induced stress signals in HT-29 human colon adenocarcinoma cells," Carcinogenesis, vol. 24, no. 8, pp. 1369-1378, 2003.

[25] M. Manohar, I. Fatima, R. Saxena, V. Chandra, P. L. Sankhwar, and A. Dwivedi, "(-)-Epigallocatechin-3-gallate induces apoptosis in human endometrial adenocarcinoma cells via ROS generation and p38 MAP kinase activation," The Journal of Nutritional Biochemistry, vol. 24, no. 6, pp. 940-947, 2013.

[26] Z. Hou, S. Sang, H. You et al., "Mechanism of action of (-)-epigallocatechin-3-gallate: auto-oxidation-dependent inactivation of epidermal growth factor receptor and direct effects on growth inhibition in human esophageal cancer KYSE 150 cells," Cancer Research, vol. 65, no. 17, pp. 8049-8056, 2005.

[27] G. Y. Yang, J. Liao, K. Kim, E. J. Yurkow, and C. S. Yang, "Inhibition of growth and induction of apoptosis in human cancer cell lines by tea polyphenols," Carcinogenesis, vol. 19, no. 4, pp. 611-616, 1998.

[28] G. X. Li, Y. K. Chen, Z. Hou et al., "Pro-oxidative activities and dose-response relationship of (-)-epigallocatechin-3-gallate in the inhibition of lung cancer cell growth: a comparative study in vivo and in vitro," Carcinogenesis, vol. 31, no. 5, pp. $902-$ 910, 2010.

[29] H. Nakagawa, "Generation of hydrogen peroxide primarily contributes to the induction of $\mathrm{Fe}(\mathrm{II})$-dependent apoptosis in Jurkat cells by (-)-epigallocatechin gallate," Carcinogenesis, vol. 25, no. 9, pp. 1567-1574, 2004.

[30] T. Nakazato, K. Ito, Y. Ikeda, and M. Kizaki, “Green tea component, catechin, induces apoptosis of human malignant $\mathrm{B}$ cells via production of reactive oxygen species," Clinical Cancer Research, vol. 11, no. 16, pp. 6040-6049, 2005.

[31] L. Tao, J. Y. Park, and J. D. Lambert, "Differential prooxidative effects of the green tea polyphenol, (-)-epigallocatechin-3-gallate, in normal and oral cancer cells are related to differences in sirtuin 3 signaling," Molecular Nutrition \& Food Research, vol. 59, no. 2, pp. 203-211, 2015.

[32] S. D. Rao and K. Pagidas, "Epigallocatechin-3-gallate, a natural polyphenol, inhibits cell proliferation and induces apoptosis in human ovarian cancer cells," Anticancer Research, vol. 30, no. 7, pp. 2519-2523, 2010.

[33] S. Shankar, G. Suthakar, and R. K. Srivastava, "Epigallocatechin-3-gallate inhibits cell cycle and induces apoptosis in pancreatic cancer," Frontiers in Bioscience, vol. 12, no. 12, pp. 5039-5051, 2007.

[34] S. Qanungo, M. Das, S. Haldar, and A. Basu, "Epigallocatechin-3-gallate induces mitochondrial membrane depolarization and caspase-dependent apoptosis in pancreatic cancer cells," Carcinogenesis, vol. 26, no. 5, pp. 958-967, 2005.

[35] C.-Y. Tsai, C.-Y. Chen, Y.-H. Chiou et al., "Epigallocatechin-3gallate suppresses human herpesvirus 8 replication and induces ROS leading to apoptosis and autophagy in primary effusion lymphoma cells," International Journal of Molecular Sciences, vol. 19, no. 1, 2018.

[36] R. M. Hagen, V. S. Chedea, C. P. Mintoff, E. Bowler, H. R. Morse, and M. R. Ladomery, "Epigallocatechin-3-gallate promotes apoptosis and expression of the caspase $9 \mathrm{a}$ splice variant in PC3 prostate cancer cells," International Journal of Oncology, vol. 43, no. 1, pp. 194-200, 2013. 
[37] I. Rady, H. Mohamed, M. Rady, I. A. Siddiqui, and H. Mukhtar, "Cancer preventive and therapeutic effects of EGCG, the major polyphenol in green tea," Egyptian Journal of Basic and Applied Sciences, vol. 5, no. 1, pp. 1-23, 2019.

[38] P. P. Wu, S. C. Kuo, W. W. Huang et al., "(-)-Epigallocatechin gallate induced apoptosis in human adrenal cancer NCI-H295 cells through caspase-dependent and caspase-independent pathway," Anticancer Research, vol. 29, no. 4, pp. 1435-1442, 2009.

[39] A. Chen, P. Jiang, F. Zeb et al., "EGCG regulates CTR1 expression through its pro-oxidative property in non-small-cell lung cancer cells," Journal of Cellular Physiology, pp. 1-12, 2020.

[40] A. Furukawa, S. Oikawa, M. Murata, Y. Hiraku, and S. Kawanishi, "(-)-Epigallocatechin gallate causes oxidative damage to isolated and cellular DNA," Biochemical Pharmacology, vol. 66, no. 9, pp. 1769-1778, 2003.

[41] H. Y. Khan, H. Zubair, M. Faisal et al., "Plant polyphenol induced cell death in human cancer cells involves mobilization of intracellular copper ions and reactive oxygen species generation: a mechanism for cancer chemopreventive action," Molecular Nutrition \& Food Research, vol. 58, no. 3, pp. 437446, 2014.

[42] M. Farhan, H. Khan, M. Oves et al., "Cancer therapy by catechins involves redox cycling of copper ions and generation of reactive oxygen species," Toxins, vol. 8, no. 2, p. 37, 2016.

[43] J. Hong, H. Lu, X. Meng, J. H. Ryu, Y. Hara, and C. S. Yang, "Stability, cellular uptake, biotransformation, and efflux of tea polyphenol (-)-epigallocatechin-3-gallate in HT-29 human colon adenocarcinoma cells," Cancer Research, vol. 62, no. 24, pp. 7241-7246, 2002.

[44] N. M. Pathak, P. J. B. Millar, V. Pathak, P. R. Flatt, and V. A. Gault, "Beneficial metabolic effects of dietary epigallocatechin gallate alone and in combination with exendin-4 in high fat diabetic mice," Molecular and Cellular Endocrinology, vol. 460, pp. 200-208, 2018.

[45] M. M. Chan, K. J. Soprano, K. Weinstein, and D. Fong, "Epigallocatechin-3-gallate delivers hydrogen peroxide to induce death of ovarian cancer cells and enhances their cisplatin susceptibility," Journal of Cellular Physiology, vol. 207, no. 2, pp. 389-396, 2006.

[46] T. C. Lee, I. C. Cheng, J. J. Shue, and T. C. Wang, "Cytotoxicity of arsenic trioxide is enhanced by (-)-epigallocatechin-3-gallate via suppression of ferritin in cancer cells," Toxicology and Applied Pharmacology, vol. 250, no. 1, pp. 69-77, 2011.

[47] P.-F. Hung, B.-T. Wu, H.-C. Chen et al., "Antimitogenic effect of green tea (-)-epigallocatechin gallate on 3T3-L1 preadipocytes depends on the ERK and Cdk2 pathways," American Journal of Physiology Cell Physiology, vol. 288, no. 5, pp. C1094-C1108, 2005.

[48] C. T. Wang, H. H. Chang, C. H. Hsiao et al., "The effects of green tea (-)-epigallocatechin-3-gallate on reactive oxygen species in 3T3-L1 preadipocytes and adipocytes depend on the glutathione and $67 \mathrm{kDa}$ laminin receptor pathways," Molecular Nutrition \& Food Research, vol. 53, no. 3, pp. 349360, 2009.

[49] E. C. Hinchy, A. V. Gruszczyk, R. Willows et al., "Mitochondria-derived ROS activate AMP-activated protein kinase (AMPK) indirectly," The Journal of Biological Chemistry, vol. 293, no. 44, pp. 17208-17217, 2018.

[50] N. Chaudhary, J. Bhardwaj, H. J. Seo, M. Y. Kim, T. S. Shin, and J. D. Kim, "Camellia sinensis fruit peel extract inhibits angiogenesis and ameliorates obesity induced by high-fat diet in rats," Journal of Functional Foods, vol. 7, pp. 479-486, 2014.

[51] N. Chen, R. Bezzina, E. Hinch et al., "Green tea, black tea, and epigallocatechin modify body composition, improve glucose tolerance, and differentially alter metabolic gene expression in rats fed a high-fat diet," Nutrition Research, vol. 29, no. 11, pp. 784-793, 2009.

[52] M. Friedrich, K. J. Petzke, D. Raederstorff, S. Wolfram, and S. Klaus, "Acute effects of epigallocatechin gallate from green tea on oxidation and tissue incorporation of dietary lipids in mice fed a high-fat diet," International Journal of Obesity, vol. 36, no. 5, pp. 735-743, 2012.

[53] M. S. Lee, S. Lee, M. Doo, and Y. Kim, "Green tea (-)-epigallotocatechin-3-gallate induces PGC- $1 \alpha$ gene expression in HepG2 cells and 3T3-L1 adipocytes," Prev Nutr Food Sci, vol. 21, no. 1, pp. 62-67, 2016.

[54] K. Yasui, N. Paeng, N. Miyoshi et al., "Effects of a catechin-free fraction derived from green tea on gene expression of enzymes related to lipid metabolism in the mouse liver," Biomedical Research, vol. 33, no. 1, pp. 9-13, 2012.

[55] W. C. Reygaert, "The antimicrobial possibilities of green tea," Frontiers in Microbiology, vol. 5, p. 434, 2014.

[56] R. A. Isbrucker, J. Bausch, J. A. Edwards, and E. Wolz, "Safety studies on epigallocatechin gallate (EGCG) preparations. Part 1: genotoxicity," Food and Chemical Toxicology, vol. 44, no. 5, pp. 626-635, 2006.

[57] L. G. Xiong, Y. J. Chen, J. W. Tong et al., "Tea polyphenol epigallocatechin gallate inhibits Escherichia coli by increasing endogenous oxidative stress," Food Chemistry, vol. 217, pp. 196-204, 2017.

[58] Y. Cui, Y. J. Oh, J. Lim et al., "AFM study of the differential inhibitory effects of the green tea polyphenol (-)-epigallocatechin-3-gallate (EGCG) against gram-positive and gramnegative bacteria," Food Microbiology, vol. 29, no. 1, pp. 80 87, 2012.

[59] T. Shimamura, W.-H. Zhao, and Z.-Q. Hu, "Mechanism of action and potential for use of tea catechin as antiinfective agent," Anti-Infective Agents in Medicinal Chemistry, vol. 6, no. 1, pp. 57-62, 2007.

[60] R. Li, J. Lu, H. Duan, J. Yang, and C. Tang, "Biofilm inhibition and mode of action of epigallocatechin gallate against Vibrio mimicus," Food Control, vol. 113, p. 107148, 2020.

[61] J. A. Imlay, "The molecular mechanisms and physiological consequences of oxidative stress: lessons from a model bacterium," Nature Reviews. Microbiology, vol. 11, no. 7, pp. 443454, 2013.

[62] T. Nie, C. Zhang, A. Huang, and P. Li, "Epigallocatechin gallate-mediated cell death is triggered by accumulation of reactive oxygen species induced via the Cpx two-component system in Escherichia coli," Frontiers in Microbiology, vol. 9, p. 246, 2018.

[63] J. Yang, C. B. Tang, J. Xiao, W. F. du, and R. Li, "Influences of epigallocatechin gallate and citric acid on Escherichia coli O157:H7 toxin gene expression and virulence-associated stress response," Letters in Applied Microbiology, vol. 67, no. 5, pp. 435-441, 2018.

[64] M. Younes, P. Aggett, F. Aguilar et al., "Scientific opinion on the safety of green tea catechins," EFSA Journal, vol. 16, no. 4, 2018.

[65] J. D. Lambert, M. J. Kennett, S. Sang, K. R. Reuhl, J. Ju, and C. S. Yang, "Hepatotoxicity of high oral dose 
(-)-epigallocatechin-3-gallate in mice," Food and Chemical Toxicology, vol. 48, no. 1, pp. 409-416, 2010.

[66] K. Nakagawa and T. Miyazawa, "Absorption and distribution of tea catechin, (-)-epigallocatechin-3-gallate, in the rat," Journal of Nutritional Science and Vitaminology, vol. 43, no. 6, pp. 679-684, 1997.

[67] B. Ramachandran, S. Jayavelu, K. Murhekar, and T. Rajkumar, "Repeated dose studies with pure epigallocatechin-3-gallate demonstrated dose and route dependant hepatotoxicity with associated dyslipidemia," Toxicology Reports, vol. 3, pp. 336345, 2016.

[68] G. Galati, A. Lin, A. M. Sultan, and P. J. O'Brien, “Cellular and in vivo hepatotoxicity caused by green tea phenolic acids and catechins," Free Radical Biology and Medicine, vol. 40, no. 4, pp. 570-580, 2006.

[69] O. Kucera, V. Mezera, A. Moravcova et al., "In vitro toxicity of epigallocatechin gallate in rat liver mitochondria and hepatocytes," Oxidative Medicine and Cellular Longevity, vol. 2015, 10 pages, 2015.

[70] D. Wang, Y. Wei, T. Wang et al., "Melatonin attenuates (-)-epigallocatehin-3-gallate-triggered hepatotoxicity without compromising its downregulation of hepatic gluconeogenic and lipogenic genes in mice," Journal of Pineal Research, vol. 59, no. 4, pp. 497-507, 2015.

[71] D. Wang, Y. Wang, X. Wan, C. S. Yang, and J. Zhang, “Green tea polyphenol (-)-epigallocatechin-3-gallate triggered hepatotoxicity in mice: responses of major antioxidant enzymes and the Nrf2 rescue pathway," Toxicology and Applied Pharmacology, vol. 283, no. 1, pp. 65-74, 2015.

[72] I. G. Saleh, Z. Ali, N. Abe et al., "Effect of green tea and its polyphenols on mouse liver," Fitoterapia, vol. 90, pp. 151-159, 2013.

[73] R. A. Isbrucker, J. A. Edwards, E. Wolz, A. Davidovich, and J. Bausch, "Safety studies on epigallocatechin gallate (EGCG) preparations. Part 2: dermal, acute and short-term toxicity studies," Food and Chemical Toxicology, vol. 44, no. 5, pp. 636-650, 2006.

[74] S. Sang, J. D. Lambert, J. Hong et al., "Synthesis and structure identification of thiol conjugates of (-)-epigallocatechin gallate and their urinary levels in mice ${ }^{\dagger}, "$ Chemical Research in Toxicology, vol. 18, no. 11, pp. 1762-1769, 2005.

[75] M. G. Goodin and R. J. Rosengren, "Epigallocatechin gallate modulates CYP450 isoforms in the female Swiss-Webster mouse," Toxicological Sciences, vol. 76, no. 2, pp. 262-270, 2003.

[76] K. Okushio, M. Suzuki, N. Matsumoto, F. Nanjo, and Y. Hara, "Methylation of tea catechins by rat liver homogenates," Bioscience, Biotechnology, and Biochemistry, vol. 63, no. 2, pp. 430-432, 2014.

[77] M. H. Kweon, V. M. Adhami, J. S. Lee, and H. Mukhtar, "Constitutive overexpression of Nrf2-dependent heme oxygenase-1 in A549 cells contributes to resistance to apoptosis induced by epigallocatechin 3-gallate," Journal of Biological Chemistry, vol. 281, no. 44, pp. 33761-33772, 2006.

[78] J. Hu, D. Webster, J. Cao, and A. Shao, "The safety of green tea and green tea extract consumption in adults - results of a systematic review," Regulatory Toxicology and Pharmacology, vol. 95, pp. 412-433, 2018.

[79] H. Inoue, S. Akiyama, M. Maeda-Yamamoto, A. Nesumi, T. Tanaka, and A. Murakami, "High-dose green tea polyphenols induce nephrotoxicity in dextran sulfate sodium- induced colitis mice by down-regulation of antioxidant enzymes and heat-shock protein expressions," Cell Stress and Chaperones, vol. 16, no. 6, pp. 653-662, 2011.

[80] M. Roghani and T. Baluchnejadmojarad, "Hypoglycemic and hypolipidemic effect and antioxidant activity of chronic epigallocatechin-gallate in streptozotocin-diabetic rats," Pathophysiology, vol. 17, no. 1, pp. 55-59, 2010.

[81] N. O. Abdel Rasheed, L. A. Ahmed, D. M. Abdallah, and B. M. El-Sayeh, "Nephro-toxic effects of intraperitoneally injected EGCG in diabetic mice: involvement of oxidative stress, inflammation and apoptosis," Scientific Reports, vol. 7, no. 1, p. 40617, 2017.

[82] E. K. Song, H. Hur, and M. K. Han, "Epigallocatechin gallate prevents autoimmune diabetes induced by multiple low doses of streptozotocin in mice," Archives of Pharmacal Research (Seoul), vol. 26, no. 7, pp. 559-563, 2003.

[83] K. O. Chu, K. P. Chan, Y. P. Yang et al., "Effects of EGCG content in green tea extract on pharmacokinetics, oxidative status and expression of inflammatory and apoptotic genes in the rat ocular tissues," The Journal of Nutritional Biochemistry, vol. 26, no. 11, pp. 1357-1367, 2015.

[84] Z. Fu, W. Zhen, J. Yuskavage, and D. Liu, "Epigallocatechin gallate delays the onset of type 1 diabetes in spontaneous non-obese diabetic mice," The British Journal of Nutrition, vol. 105, no. 8, pp. 1218-1225, 2011.

[85] Y. C. Fan and W. H. Chan, "Epigallocatechin gallate induces embryonic toxicity in mouse blastocysts through apoptosis," Drug and Chemical Toxicology, vol. 37, no. 3, pp. 247-254, 2013.

[86] B. Bertram, U. Bollow, N. Rajaee-Behbahani, A. Bürkle, and P. Schmezer, "Induction of poly(ADP-ribosyl)ation and DNA damage in human peripheral lymphocytes after treatment with (-)-epigallocatechin-gallate," Mutation Research/Genetic Toxicology and Environmental Mutagenesis, vol. 534, no. 1-2, pp. 77-84, 2003.

[87] H. S. Liu, Y. H. Chen, P. F. Hung, and Y. H. Kao, "Inhibitory effect of green tea (-)-epigallocatechin gallate on resistin gene expression in 3T3-L1 adipocytes depends on the ERK pathway," American Journal of Physiology Endocrinology \& Metabolism, vol. 290, no. 2, pp. E273-E281, 2006.

[88] A. A. Yates, J. W. Erdman Jr., A. Shao, L. C. Dolan, and J. C. Griffiths, "Bioactive nutrients - time for tolerable upper intake levels to address safety," Regulatory Toxicology and Pharmacology, vol. 84, pp. 94-101, 2017.

[89] G. Robertson, I. Leclercq, and G. C. Farrell, "Nonalcoholic steatosis and steatohepatitis. II. Cytochrome P-450 enzymes and oxidative stress," American Journal of Physiology. Gastrointestinal and Liver Physiology, vol. 281, no. 5, pp. G1135G1139, 2001. 